\title{
FURTHER REMARKS ON THE HEART IN DEBILITY.
}

\author{
By G. A. Gibson, M.D., D.Sc., F.R.C.P.Ed., Assistant Physician, \\ Royal Infirmary, Edinburgh.
}

Mr contribution to this Journal 1 with regard to the condition of the heart in debility was prompted by the feeling that the demands of honesty, to say nothing of the dictates of honour, required a frank and candid statement of the change in my views on this subject. It goes without saying that my remarks indicated considerable difference in opinion from the teaching of Balfour, and, in the present volume of the Journal, ${ }^{2}$ my friend and teacher has dealt with some of my statements. In his criticism he has confined his attention almost entirely to the systolic impulse in the second left intercostal space, and to the murmur which accompanies it; and to these points the following remarks will be mainly restricted.

The observations made by me with the cardiograph many years ago on the pulsation in the second left intercostal space led me to the conclusion that the pulsation was, as Balfour believes, due to regurgitation from the left ventricle into the left auricle. The reasons leading me to this conclusion were twofold-(1) the pulsation was not in advance of the apex beat, as it would have been were the pulsations due to auricular systole, the only alternative which presented itself to my mind at the time of our old discussions; and (2) the form of the curve was often somewhat like that obtained from the apparent apex. The first suspicion of doubt entering my mind occurred during my long series of observations on the cardiac cycle, ${ }^{3}$ the opportunity for which was furnished by the instance of sternal fissure described by Malet and myself. ${ }^{4}$ The fact that pulsation obviously produced by the conus arteriosus could yield cardiographic curves, sometimes not unlike those obtained in conditions of debility from the pulsation in the second left intercostal space, made it clear that there was a possibility of mistake. The further fact that the impulse of the conus arteriosus and the pulsation of the carotid arteries were simultaneous, was a further step in the same direction.

1 Journ. Path. and Bacteriol., Edin and London, 1895, vol. iii. p. 32.

2 Ibid., 1896, vol. iv. p. 75 .

${ }^{3}$ Journ. Anat. and Phys., London, 1880, vol. xiv. p. $234 . \quad{ }^{4}$ Ibid., vol. xiv: p. 1. 
Even more important, however, as an argument is the fact that weil-nigh twenty years' assiduous search in the post-mortem theatre for any instance of an auricular appendix, which could by any possibility have given rise to the pulsation so often found in life, has been absolutely fruitless. Instead of at any time finding such an enlarged appendix, the only probable source of the pulsation seen by me on postmortem examination has been, as Russell correctly stated, the conus arteriosus itself.

The heart described by Balfour in his criticism of my paper shows a considerable enlargement of the appendix of the left auricle. "Such auricles," Balfour says, "are not uncommon; I have seen scores of them both during life and after death." This interesting statement does not affect the question at issue, but to the remark that, " in this case not only the apex of the appendix auriculi, but a considerable portion of the appendix itself, must have been in the closest juxtaposition with the anterior chest wall," exception must be taken. From a careful examination of the heart in question it is clear that, on account of the bulging of the conus arteriosus, the left auricular appendix would probably not be in contact with the chest wall at any point. The figure which accompanies the paper is in itself sufficient to show this. The heart has with perfect candour been photographed in profile, and it will be seen that the auricular appendix is distinctly behind the level of the conus arteriosus and pulmonary artery. It is unfortunate that there are no details with regard to the physical signs presented by the patient during life. From the appearance of the heart, when seen from the front instead of from the side, it would not be surprising to hear that a pulsation had existed in the second left intercostal space, but that pulsation would in my opinion have been produced by the conus arteriosus.

Dilatation of the left auricle and of its appendix, accompanied by a certain amount of hypertrophy, is an extremely common experience in the post-mortem theatre; but in how few of the cases showing such pathological conditions after death has there been any pulsation in the second intercostal space during life!

One most important point connected with mitral regurgitation must be adverted to. Balfour holds that in the condition under discussion there is mitral regurgitation of a kind which is to be regarded as a "vital phenomenon." "So soon," he says, "as residual accumulation and ventricular failure together are sufficient to keep the insertions of the chordæ tendineæ so wide apart that the trifling pressure of the blood flowing from the auricle is unable to bring the valve segments into apposition, then the moment the ventricular systole commences we have regurgitation between these segments into the auricle." He further remarks that the regurgitation "gives rise to fluid veins which impinge upon the wall of the left auricle, exciting in it sonorous vibrations that give rise to an audible murmur at the only 
point at which that auricle approximates the anterior chest wall. This systolic murmur does not reach the chest wall in the usual position, which is over the apex beat, apparently because the vibrations of the ventricular wall are too feeble to be sonorous, or are not sufficiently so to be communicated to the chest wall in this position, otherwise than as a mere impurity of the first sound; a state of matters no doubt greatly favoured by the separation of the left apex from the chest wall by the dilated right ventricle." When this line of argument is carefully considered it must be obvious that certain fallacies underlie it. Passing by the explanation that the vibrations of the ventricular wall are too feeble to be sonorous-a matter as incapable of proof as of disproof - it is perfectly clear that the reasoning breaks down as regards one important point. If the left apex is separated from the chest wall by a dilated right ventricle, there cannot be the shadow of a doubt that the left auricle will be also further removed from the thoracic parietes by the same cause, and the argument as regards this aspect of the subject is therefore open to question.

Such are the considerations which have led me to renounce the ingenious and attractive theory now under discussion-a theory enthusiastically supported by me in former years. 